\title{
QUOD VI AGAT FEMINAM. AUTORIDAD MARITAL Y VIOLENCIA DOMÉSTICA EN EL DISCURSO NORMATIVO Y PATRÍSTICO DE LA HISPANIA TARDOANTIGUA
}

\author{
POR \\ Henar Gallego Franco ${ }^{1}$ \\ Universidad de Valladolid
}

\section{RESUMEN}

Desde el marco metodológico de los estudios especializados sobre la violencia doméstica y el maltrato de la casada en la Antigüedad tardía, el trabajo analiza los textos legislativos seculares y canónicos y el discurso patrístico cristiano producido en Hispania en este período (ss. V-VII d. C.) para explorar la relación entre los conceptos de matrimonio y de autoridad marital, tal y como se reflejan en estas fuentes, y la posibilidad de un ejercicio legitimado de violencia de los maridos sobre las mujeres casadas en la sociedad hispana tardoantigua. Se contribuye también a situar a dicha sociedad en el contexto de las construcciones socioculturales comunes del Occidente tardoantiguo vinculadas al problema histórico de la violencia doméstica y marital.

PALABRAS CLAVE: autoridad marital; matrimonio cristiano; violencia de género; Hispania tardoantigua.

\section{QUOD VI AGAT FEMINAM. HUSBAND'S AUTHORITY AND DOMESTIC VIOLENCE IN THE NORMATIVE AND THE PATRISTIC DISCOURSE OF HISPANIA IN LATE ANTIQUITY}

\begin{abstract}
On the methodological background of the studies about domestic violence and wife beating in Late Antiquity this work analyses thoroughly the secular and religious legislative texts and the Christian patristic discourse produced in Hispania in this period (Vth to VIIth centuries) to explore the bounds between the concepts of marriage and husband's authority as they are reflected in these sources and the possibility of a legitimized practise of a direct violent against married women by their husbands in the Spanish society in Late Antiquity. Lastly this study has the aim of contributing to place the Spanish society in the context of the common socio-cultural constructions of the Latin Occident related to the historical topic of the violence against women in Late Antiquity.
\end{abstract}

KEY WORDS: Husband's authority; Christian marriage; Gender violence; Hispania; Late Antiquity.

CÓMO CITAR ESTE ARTíCULO / CITATION: Gallego Franco, H. 2018. "Quod vi agat feminam. Autoridad marital y violencia doméstica en el discurso normativo y patrístico de la Hispania tardoantigua». Hispania Sacra 70, 142: 395-405. https://doi.org/10.3989/ hs.2018.026

Recibido/Received 14-03-2017

El matrimonio, según se concibe en las estructuras normativas seculares y religiosas que sustentan la sociedad de la Hispania tardoantigua (ss. V-VII d. C), es una institución que ejerce una violencia estructural sobre las mujeres. ${ }^{2}$ Ello es así debido a que carecen de libertad reconocida para

\footnotetext{
henarg@fyl.uva.es / ORCID iD: http://orcid.org/0000-00026750-1075

2 Sobre el concepto de violencia estructural sobre las mujeres puede verse González Mínguez 2008: 16; Molas Font 2007: 10, «Introducción»; Sánchez Romero 2007: 43-44; Jiménez y Muñoz 2004: 1161 1162 y $1165-1168$.
}

elegir a su futuro marido y están supeditadas a él en todo. Es el marido el que administra el patrimonio de la casada, su representante legal, su tutor moral, el que controla su cuerpo y gobierna su sexualidad (que se considera legítima en tanto dirigida a la reproducción), un marido del que no pueden divorciarse, al que deben sumisión y obediencia, y que dispone de derecho y deber de corrección respecto del comportamiento de su mujer. ${ }^{3}$ Partiendo de este marco

3 Gallego Franco 2005: 339-350. En realidad, la situación general de subordinación e inferioridad en la que viven las mujeres es, en sí misma, violenta. Segura Graíño 2008: 30. 
general, en el que el concepto de autoridad marital resulta básico, este trabajo tiene el objetivo de explorar en los textos normativos, seculares y religiosos y en el discurso patrístico de la Hispania tardoantigua, la existencia de conexiones entre la concepción del matrimonio y de la autoridad marital en la época y la posibilidad de un ejercicio legitimado de violencia directa de los maridos sobre sus mujeres. Quiere también contribuir a situar a la sociedad hispana en el contexto de las construcciones socio-culturales comunes del Occidente tardoantiguo vinculadas al problema histórico de la violencia doméstica y marital. ${ }^{4}$

Las leyes y el derecho constituyen un elemento esencial en el estudio de los procesos de legitimación de la violencia contra las mujeres casadas en el mundo antiguo. Joy A. Schroeder, en su ya clásico trabajo sobre la crítica a la violencia marital y doméstica en la obra de Juan Crisóstomo, inicia su aproximación al tema recordando una afirmación de Peter Brown, que repito aquí traducida: «Estamos en un mundo que se caracteriza por una ausencia escalofriante de restricciones legales acerca de la violencia en el ejercicio del poder $\gg .{ }^{5}$ Nuestro conocimiento de las fuentes normativas nos permite hacer extensible esta afirmación al ejercicio del poder conyugal en la familia tardoantigua, que corresponde, como es bien sabido, al marido. En el derecho romano postclásico no estaba prohibido el castigo físico de un marido hacia su mujer, ni el maltrato de la casada se contemplaba como delito, a excepción del homicidio. ${ }^{6}$ Las mujeres apenas contaban con instrumentos legales a su alcance para detener cualquier conducta violenta de sus maridos, salvo solicitar un divorcio para el que el derecho imperial tardorromano había reducido enormemente las posibles causas legítimas de la iniciativa femenina. ${ }^{7}$ Por ende, cabe considerar que la

4 Sin ánimo de exhaustividad, el interés de los especialistas por el fenómeno de la violencia doméstica, y la violencia de género en general, en el mundo grecorromano y con atención especial a la Antigüedad Tardía, ha generado publicaciones muy notables en los últimos tiempos: Clark 1998: 109-129; Clark 2006: 137-146 y 2015; Cooper 2007; Dossey 2008: 3-40; Molas Font 2007; Molas Font, Guerra, Huntingford y Zaragoza 2006; Osaba 2011: 125-148; Pérez Cantó 2009; Schroeder 2004: 413-432.

5 Brown 1992: 50. Citado en Schroeder 2004: 414, nota 3.

Ibídem: 416; Dossey 2008: 5-7.

Los especialistas coinciden en que tanto en el derecho postclásico de Occidente, como en el derecho justinianeo, las causas de anulación del matrimonio eran cada vez menos: Beaucamp 1990: 170; Evans-Grubbs 1993: 128; Teschendorff 2005: 124-129; Urbanik 2013: 259-272. No obstante, Dossey incide en el divergente comportamiento de la legislación imperial de la pars orientalis y la pars occidentalis del Imperio Romano respecto a este asunto, siendo la primera más favorable para la protección de las casadas frente a la violencia marital (2008: 5-6). La legislación imperial de Oriente durante los ss. V y VI reconocía el derecho de las mujeres casadas a divorciarse o, a partir de Justiniano, a recibir una compensación financiera de los maridos que las golpeaban con palos o flagelos (Nov. Th. II, 12, 1, 439 d. C.; CJ V, 17, 8, 449 d. C.; Nov. lust. XXII, 15, 30; CXVII, 14). Es cierto que resulta una protección imperfecta, ya que cubría únicamente una determinada forma de ejercer la violencia marital, con verbera $u$ otros instrumentos propios del castigo de esclavos y no aptos para la dignidad de una mujer libre, y las multas se aplicaban solo cuando el maltrato no estaba causado por una razón sancionada legalmente como motivo de repudio de la mujer, en esencia la infidelidad de la misma o cualquier tipo de comportamiento que llevara al marido a sospechar ésta (cenar o acudir a los baños con otros hombres, o pasar la noche fuera de casa sin permiso del marido). Sin embargo, la legislación imperial de Occidente no reconocía a las mujeres la posibilidad de divorciarse disponibilidad de divorcio podría ejercer un efecto protector frente al maltrato en el caso de aquellas mujeres de alto nivel socioeconómico, ya que una mujer casada al divorciarse se llevaba con ella, como mínimo, su dote, además de sus bienes personales, una pérdida patrimonial no deseada por el marido. Pero poca protección aportaría a las mujeres humildes, cuyo sostén económico y el de su prole se lo procuraba su marido, según el orden de género vigente; de manera que tendrían que escoger entre soportar los golpes o exponerse a la miseria. ${ }^{8}$ La ausencia de sanciones al marido maltratador y la práctica imposibilidad de las mujeres de acceder a un divorcio por iniciativa propia eran rasgos también presentes, en general, en los nuevos códigos de justicia emanados de los emergentes reinos bárbaros de Occidente. ${ }^{9}$ Desde la perspectiva hispana, el estudio del tratamiento que el maltrato de la casada recibe en las leyes que afectan a la sociedad tardoantigua, y dado que ya nos hemos referido más arriba al marco general de la legislación imperial tardorromana, debe dirigir nuestra atención a la legislación propia emanada del estado monárquico hispano-visigodo (ss. VI-VII d. C.), que toma su forma completa en la Lex Visigothorum (L. V.) promulgada por Recesvinto el año 654 d. C. ${ }^{10}$

Esta legislación ni considera ni penaliza la violencia marital, si bien recoge el homicidio de uno de los cónyuges, que es incluido en el ámbito del delito de parricidio, tratado en L. V. VI, 5, 17-19. ${ }^{11}$ Resulta, por tanto, que el legislador no contempla la posible existencia de una violencia directa no

de un marido maltratador o que este fuera multado por este comportamiento. De hecho, eliminaba en la práctica la posibilidad de divorcio unilateral para las mujeres desde época de Honorio (CTh III, 16, 2, 421 d. C.; Nov. Val. III, 35, 11, 452 d. C.).

Otros factores pueden impulsar a una mujer a mantenerse en una convivencia conyugal violenta: el temor a perder a sus hijos, puesto que en las leyes romanas normalmente el paterfamilias se quedaba con su custodia, al ser el único con patria potestas sobre ellos, y, en una sociedad cristiana, el miedo a la desaprobación eclesiástica y social que provocaba el divorcio y las segundas nupcias, cfr. Churruca 1998: 32-33; Clark 1998: 127-128, nota 16; Schroeder 2004: 417, nota 19. Sobre la desaprobación de las segundas nupcias y el divorcio en la Hispania tardoantigua, Gallego Franco 2002: 624 y 2010: 245-247; Fernández Ubiña 2005: 308-314.

9 Las leyes emanadas de las monarquías ostrogoda, burgundia, franca o visigoda muestran igualmente un tratamiento muy restrictivo de las causas del divorcio por iniciativa femenina, enorme severidad en las penas para las mujeres adúlteras y una ausencia de multas u otras protecciones a las casadas maltratadas. Pero además la capacidad legal del marido para ejercer violencia sobre la mujer se incrementó en el hecho de que podía matarla si la sorprendía en adulterio flagrante, una acción que en el derecho romano clásico había pertenecido al padre y no al marido de la mujer. Cfr. Arjava 1996: 199; Dossey 2008: 7; Schroeder 2004: 416, nota 11; Wemple 1981: 42 y 223-224, nota 83.

10 Lex Visigothorum o Liber ludicum/El Fuero Juzgo, Los códigos españoles comcordados y anotados 1847: 1-86 y 97-201.

11 L. V. VI, 5, 17 de Chindasvinto, y las antiquae 18 y 19, cfr. D'Ors 2014: 114. La pena es la muerte o el exilio, y la pérdida patrimonial total a favor de los herederos del muerto/a. El responsable es exonerado en el supuesto de defensa propia. En $L$. V. VI, 5, 18 la muerte de la mujer a manos del marido o del marido a manos de la mujer es el único ejemplo de parricidio presentado por el legislador implicando personas de distinto sexo, mientras que en los restantes ejemplos se describe el delito manteniendo el recurso retórico de una separación de sexos, por ejemplo, si el padre mata al hijo o el hijo al padre, o la madre mata a la hija y la hija a la madre, el hermano al hermano y la hermana a la hermana. Una síntesis del tratamiento del uxoricidio en el derecho romano clásico, en el que también estaba tipificado como parricidio, en Pavón 2011: 258-261. 
legítima ejercida por los maridos sobre sus mujeres, pero, significativamente, sí considera y penaliza el ejercicio de una violencia directa y no legítima de los dueños y dueñas sobre sus siervos. ${ }^{12}$ El legislador no considera los posibles excesos en el ejercicio de la autoridad marital pero sí en el ejercicio de la potestad de los dueños. Ciertamente, para considerar delito legal el maltrato de las mujeres casadas por sus maridos una comunidad tiene que considerarlas como sujetos de derechos iguales a los hombres, concepto ajeno a las sociedades preindustriales. Pero tampoco los siervos disponían de los mismos derechos que los libres y sin embargo son aquí protegidos de la crueldad injustificada de sus dueños.

Por otro lado, la Lex Visigothorum se preocupa por establecer de forma muy clara la autoridad del marido sobre su mujer y la posición subordinada de ésta en el orden conyugal. ${ }^{13}$ Esta consideración subordinada de la mujer casada afecta a todas ellas, con independencia de su estatus legal y nivel socioeconómico, y se transmite a los códigos legislativos hispanos posteriores, como las Partidas, en sintonía con los europeos. Se indica de forma explícita en L. V. IV, 2, 15 , ley de Recesvinto que incorpora a los bona paterna las ganancias obtenidas por el marido en las campañas militares con los siervos de su mujer, y excluye toda posible reclamación de ésta, lo que se justifica señalando que, según la Sagrada Escritura, en alusión a Gen. 3, 16, la mujer está bajo la potestad del marido, y por tanto sus siervos también. Esta ley reproduce, incluida idéntica expresión sobre la potestad marital (vir, cui uxorem suam secundum sanctam scripturam habet in potestate), otra del Código de Eurico (CE 323), también emanada de la monarquía visigoda pero anterior en casi dos siglos. Esta coincidencia muestra el hondo arraigo de la noción de potestad marital en el derecho emanado de la monarquía visigoda así como del recurso de su justificación teológica. ${ }^{14}$ Se sustenta aquí la subordinación de la mujer a su marido en la principal fuente de verdad en el mundo antiguo, el texto religioso revelado, lo que convierte la potestad marital en un principio sancionado por la divinidad. Es decir, el discurso cristiano viene aquí en ayuda de la normativa secular para subrayar la «naturalidad» y "sacralidad» del orden conyugal y la autoridad marital. Es por ello que, respecto a la autoridad marital, se observa en la Antigüedad tardía hispana una sintonía entre el discurso de los textos normativos emanados del poder secular y el discurso normativo y patrístico cristiano, aspecto en el que incidiremos a continuación. En realidad, el discurso patrístico tiene gran influencia sobre la legislación secular y canónica, y en general sobre las élites políticas e intelectuales de la época, de las que, en definitiva, emana el discurso legal.

12 L. V. VI, 5, 12 y 13, dos leyes del s. VII. Estas protegen a los siervos y siervas de ser mutilados o matados por sus dueños y dueñas sin causa justificada, "por crueldad» (quia saepe praesumptionem crudelium dominorum extra culpam servorum animae perimuntur) o "furor» (in eo furore servum aut ancillam occiderint) y al margen de la intervención de los tribunales de justicia, pero obviamente se permite la violencia por causa justificada. Sin embargo, la norma no considera la posibilidad de que los maridos maltrataran a sus mujeres por crueldad o por furor, lo que sí contempla en el caso de los dueños y dueñas de siervos y siervas.

13 Osaba 2013: 121-123.

14 L. V.IV, 2, 15, [...] sed vir, cui uxorem suam secundum sanctam scripturam habet in potestate, similiter et in servis eius potestatem habebit. Para CE 323, D’Ors 2014: 38-39.
El concepto de autoridad del marido sobre la mujer subyace también en $L$. $V$. III, 1, 2, en donde Leovigildo anula la prohibición de matrimonios mixtos entre godos y romanos, dejando como único requisito prevalente el de la igualdad de los cónyuges en rango y dignidad, al indicar que se contraigan las nupcias «con el acompañamiento acostumbrado del consenso del linaje» (prosapiae solemniter consensus). Esta observación responde seguramente a la creencia de que los matrimonios desiguales en dignidad ponen en entredicho el sometimiento de la mujer al marido. ${ }^{15}$ Isidoro de Sevilla (c. 556-636 d. C.), gran figura intelectual y eminente autoridad eclesiástica de la Hispania visigoda, expresa este peligro claramente en De Ecclesiaticis Officiis cuando afirma: «porque muchas (casadas), ante aquellos maridos más sencillos, arrastradas por los vientos de las riquezas y de la nobleza, no se acuerdan de las palabras por las que Dios hizo que estuvieran sujetas a sus maridos». ${ }^{16}$ De nuevo la sujeción de la mujer al marido aparece justificada por el orden divino.

En realidad, la conveniencia de la similitud del rango social de los cónyuges para garantizar un matrimonio exitoso forma parte del fondo común de creencias acerca del matrimonio en la sociedad grecorromana clásica y postclásica. ${ }^{17}$ En relación al discurso patrístico, es interesante mencionar aquí la aportación de Juan Crisóstomo respecto a este asunto, quien también estimaba que las nupcias desiguales lesionaban la armonía conyugal, pero añadía a este peligro otro efecto no deseado, el de la violencia conyugal, ya que afirmaba que las mujeres ricas tendían a perpetrar violencia verbal y emocional sobre sus maridos de rango social y económico más bajo, cuya dependencia financiera les podía llevar, a su vez, a reacciones violentas. ${ }^{18}$ Nótese que mientras Crisóstomo señala la violencia conyugal como un efecto real y perverso de la desigualdad en las nupcias, Isidoro ignora, como el mismo legislador, esta posibilidad, y expone, como efecto principal, la subversión del orden conyugal en sí misma, la no sujeción de la mujer al marido.

La importancia que concede la Lex Visigothorum a la similitud de rango social de los cónyuges se retoma de nuevo en el proemio de $L V$. III, 1, 5, ley de Recesvinto, que establece que el acuerdo para el matrimonio debe ser establecido con la concordia de las debidas solemnidades (totius solemnitatis concordia), siendo éstas las condiciones apropiadas respecto a la edad de los cónyuges, cuestión que se aborda en esta ley, y el respeto a la dignidad social de ambos, que no se trata aquí en detalle porque ya se había abordado en otras leyes, por ejemplo la que comentamos más arriba de Leovigildo. ${ }^{19}$ En relación a la edad de los cónyuges, esta ley señala que la prometida tiene que ser de menor edad que el prometido:

Ya que si los hombres han recibido tal nombre para que ejerzan su dominio (vis, fuerza) sobre las mujeres (quod vi feminas agant), ellos, en un empeño contrario a la naturaleza, anteponen las jovencitas a los varones cuando unen en esponsales a jóvenes adolescentes con niños pequeños. Y así, invirtiendo el orden de la edad,

\footnotetext{
15 Así lo entiende también Sanz Serrano 2000: 403.

16 Isidoro, De Eccl. Off., XX, 1: se refiere Isidoro a san Pablo, Col., 3, 18 y Gen. 3, 16. Urdeix 2011: 103.

17 Similares prejuicios en la Roma clásica, Treggiari 1991: 89 y 238-241.

18 Schroeder 2004: 423-424, sobre Crisóstomo en De Virginitate. 19 Osaba 2011: 130-132, 140.
} 
violentan el bien de la honestidad por causa de la impudicia, ya que la mayor edad y superior ímpetu de las jóvenes desdeña esperar el crecimiento más lento y tardío de los varones. ${ }^{20}$

Se refiere la ley a aquellos padres que arrastrados por la codicia (inlectos cupiditatis ardore) establecen compromisos nupciales sin concordancia de edad ni de costumbres (nec etatum concors sit ordo, nec morum). Efectivamente, el deseo de asegurar una unión ventajosa económicamente para sus respectivas familias podía propiciar este tipo de esponsales, especialmente entre la nobleza. ${ }^{21}$ La norma legal establece aquí una conexión entre los términos latinos vir, varón, y vis, fuerza, ésta última, asevera con carácter general, definitoria de la naturaleza del varón (illa dederit nomen) y del dominio que estos están llamados a ejercer sobre las mujeres (quod vi feminas agant). Por ello, se indica, es la honestidad la que sale perdiendo al comprometer a jovencitas con niños, porque el mayor ímpetu (avidior, la mayor pasión/deseo) de ellas, en pleno despertar sexual adolescente, no encuentra enfrente a un hombre capaz de gestionarlo con la necesaria vis (fuerza), al ser los prometidos todavía niños lentos y torpes (seros tardosque), y ello propicia que las muchachas busquen satisfacer sus deseos fuera del orden establecido. ${ }^{22}$

Con anterioridad a la promulgación de la Lex Visigothorum, esta relación entre los términos varón (vir) y fuerza (vis) había sido ya recogida por Isidoro de Sevilla en las Etimologías, cuando se refiere al origen de la palabra vir:

El nombre de varón (vir) se explica porque en él hay mayor fuerza (vis) que en la mujer; de aquí deriva también el nombre de virtud (virtus); o tal vez porque domina a la mujer por la fuerza (quod vi agat feminam). La mujer, mulier, deriva su denominación de mollities, dulzura, como si dijéramos mollier... La diferencia entre el hombre y la mujer radica en la fuerza y en la debilidad de su cuerpo. Es mayor en el varón y menor en la mujer la virtud (virtus), para que la mujer pudiera soportarlo y, además, no fuera que, al verse rechazado por la mujer, el marido se viera empujado por su concupiscencia a buscar otra cosa o deseara el placer homosexual. ${ }^{23}$

Este binomio vir/vis pertenece a las concepciones socioculturales clásicas en torno a la masculinidad dominante

20 L. V. III, 1, 5 [...] Nam cum viris res illa dederit nomen, quod vi feminas agant, sti per repugnantia nature conamina maribus puellulas anteponunt, dum infantibus adulescentulas disponsationis copula iungunt. Es un fragmento del proemio de esta ley que es analizado en detalle en Osaba 2011: 125-148.

21 García Moreno 1986: 422.

22 En la Antigüedad tardía hispana la adolescencia era considerada una "edad difícil», tanto para los muchachos como las muchachas, caracterizada por el despertar del deseo sexual y su incontinencia, $c f r$. Gallego Franco 2003: 422-423, nota 50; García Iglesias 1976: 79-96.

${ }_{23}$ Isidoro, Etymologiae, XI, 2, 17 y 19: Vir nuncupatus, quia maior in eo vis est quam in feminis: unde et virtus nomen accepit; sive quod vi agat feminam [...] Vtrique enim fortitudine et inbecillitate corporum separantur. Sed ideo virtus maxima viri, mulieris minor, ut patiens viri esset; scilicet, ne feminis repugnantibus libido cogeret viros aliud appetere aut in alium sexum proruere. Oroz y Marcos 1982. El texto en cuestión bebe en la amplia tradición patrística occidental, y así el norteafricano Lactancio afirmaba también, a comienzos del s. IV d. C., que «Dios dio a los hombres más fortaleza física (robor) que a las mujeres para que los hombres pudieran más fácilmente obligar a las mujeres a soportar el yugo marital», cfr. Lactancio, De Opificio Dei, XII, 16 en Dossey 2008: 15, nota 52. romana, en las que la fuerza era un componente prevalente, asociado a la virtus. ${ }^{24}$ Éstas contribuyeron a generar una sólida tradición de legitimación del uso de la fuerza en las relaciones de subordinación gestionadas por el paterfamilias, que se extiende hasta la sociedad occidental tardorromana. ${ }^{25} \mathrm{El}$ deber de disciplinar a los inferiores caracteriza al paterfamilias romano, legitima el uso de la violencia física en aras de la corrección de las conductas equivocadas de aquellos bajo su autoridad (mujer, hijos, esclavos), y, al mismo tiempo, es expresión de su preocupación por ellos. ${ }^{26}$ Estos valores familiares y domésticos son cristianizados y asumidos por el discurso patrístico occidental tempranamente. En los escritos de Agustín de Hipona esta disciplina muestra el "amor duro» del paterfamilias hacia ellos, hacia los que están sometidos a él, igual al amor de Dios, el padre amante último que inflige dolor saludable a sus hijos. ${ }^{27}$ Esta noción, transportada a la esfera pública y allí sublimada, la encontramos, por ejemplo, en el discurso de las fuentes hispanovisigodas acerca de las virtudes del monarca, y, así, sobre los deberes virtuosos del príncipe, afirma el arzobispo e intelectual Julián de Toledo (c. 642-690 d. C.) que muestra «una cólera dirigida más a la corrección de las faltas de los rebeldes que contra sus propias personas ${ }^{28}$

24 Isidoro reproduce a Lactancio cuando deriva la etimología de "hombre» (vir) de "fuerza» (vis) y la de "mujer» (mulier) de "blandura» (mollities), Isidoro, Etymologiae, XI, 2, 17 y 19; Lactancio, De Opificio Dei, XII, 16-17 y Dossey 2008: 33, nota 127 . En todo caso, la consideración de la fuerza y la dureza como componentes esenciales e identitarios de la masculinidad procede ya de la Roma clásica, Bonfante 1987: 197-198; Dossey 2008: 33 y 37-40; McDonnell 2006: 72-73, nota 3.

25 Dossey 2008: 33 y 37-40; Urbanik 2013: 264 y 269-270. La fuerza y el dominio eran características naturales de los varones y la propia obedencia a las órdenes es altamente valorada por la masculinidad romana, muy sensible hacia el respeto a la jerarquía: para san Agustín, por ejemplo, la obediencia a las órdenes es la madre de todas las virtudes, señalando que una esposa obediente debe ser preferida a una virgen desobediente, cfr. Lamberigts 2014: 377.

26 Se pregunta Dossey (2008: 38) por qué los romanos eran tan sensibles a las infracciones de los inferiores, una sensibilidad que justificaba el uso de la ira y la violencia en las rebeliones de esclavos, provinciales y mujeres, señalando que los estudios de masculinidades comparadas sugieren que una sensibilidad tan extrema surge cuando la frontera entre los sexos y la construcción de género asignada a cada uno de ellos no es rígida, sino fluída, añadiendo que, en el pensamiento romano, la naturaleza «construida» de las categorías humanas (mujer, esclavo), y no «biológica» o «natural», era, hasta cierto punto, reconocida. En esta linea, resulta relevante el análisis de Núñez de Paz (2015: 375-381), basado en textos de intelectuales, filósofos y juristas altoimperiales, en los que se explicita la conciencia de que el principio tradicional de inferioridad (imbecillitas) de las mujeres tiene su origen en las mores (las costumbres) y no en la naturaleza; sin embargo la intelectualidad cristiana prefirió vincularse al discurso tradicional de las naturales incapacidades femeninas y la exclusión de las mujeres de las funciones civiles y públicas.

27 Ver De Bruyn 1999: 264-273. Con posterioridad, Clark 2006: 143, nota 36; Moreira 2006: 148-149; Pedregal 2015: 270-271. Clark subraya cómo Agustín vincula la violencia doméstica legitimada con la violencia político-religiosa legitimada, ambas emanan del «amor duro» del padre, del marido, del monarca y de Dios por los suyos, y de su poder de corrección en cada caso. También Dossey 2008: 10-11 y Schroeder 2004: 431.

28 Julián de Toledo, Historia Wambae regis, 22, 583 en García Herrero 1991: 242. Cfr. también Isidoro, Sententiae, I. 3, c. 50, 1 (Sobre la paciencia de los príncipes): «Es frecuente que el príncipe justo sepa disimular aun los extravíos de los malos, no porque consienta en su iniquidad, sino porque aguarda el tiempo propicio para la corrección, en el que pueda o bien enmendar sus vicios o bien castigarlos». Campos y Roca (trad.) 1971. 
Es decir, una cólera que en última instancia es correctora de comportamientos, aunque es obvio que también causa daño a la persona corregida. En definitiva, el concepto de la autoridad marital reflejado en el discurso legal y patrístico hispanovisigodo se enraíza en las concepciones tradicionales romanas de la autoridad del jefe de familia y su deber de disciplina.

Por otro lado, las afirmaciones de Isidoro de que la mayor fuerza del hombre sirve al propósito de poder dominar a la mujer se complementan con la creencia, heredada del mundo clásico, de que la hembra es más libidinosa que el macho en cualquier especie, es decir, es concupiscente de forma «natural», que recoge también en las Etimologías. ${ }^{29}$ Su hermano, el también obispo e intelectual Leandro de Sevilla (c. 534-596 d. C.), en su obra De institutione virginum, afirma que lo único que detiene de verdad a las mujeres coquetas de realizar adulterio es el temor al marido, aunque fornican en su interior. ${ }^{30}$ La autoridad marital, ejercida gracias a la vis, sirve así de freno a la naturaleza incontinente y poco virtuosa de las mujeres. ${ }^{31}$ Leandro compara también la situación de la casada con la de una esclava, adquirida por su marido con el pago de la dote y subordinada a él en todo $^{32}$, apropiándose aquí de una retórica ya manejada por Agustín de Hipona, quien en sus sermones había hablado de los contratos de matrimonio como documentos de compra que hacen de la mujer la esclava (ancilla) de su marido (dominus). ${ }^{33}$ Precisamente, Crisóstomo, insiste en que la

29 Isidoro, Etymologiae, XI, 2, 24: «(Sobre la etimología de femina) [...] Otros creen que la etimología es griega, haciendo derivar el nombre de fémina de la fuerza del fuego, porque su concupiscencia es muy apasionada: se afirma que las hembras son más libinidosas que los hombres tanto entre las mujeres como entre los animales». (Alii Graeca etymologia feminam ab ignea vi dictam putant, quia vehementer concupiscit. Libidinosiores enim viris feminas esse tam in mulieribus quam in animalibus). Se genera así una imagen contradictoria sobre la sexualidad de las mujeres, a las que se supone libidinosas y tendentes al descontrol, pero de las que se espera castidad y una sexualidad pasiva y controlada, Gallego Franco 2003: 424-425.

30 Leandro, De inst. virg., 268-269. Esta obra es una mezcla de tratado teológico sobre la virginidad y de regla monástica, dedicado a su hermana Florentina, monja conventual. Dentro de la corriente patrística que exalta la virginidad consagrada como superior opción de vida para las mujeres que la del matrimonio, conocemos en la Hispania tardoantigua varios tratados sobre la virginidad además del de Leandro: una carta del obispo Osio de Córdoba en alabanza de la virginidad, y sendos libelos de los obispos Avito y Severo de Málaga, todos ellos para respectivas hermanas (Isidoro, De viris illustribus, I, 1-3, XXIII, 5-7, XXVIII, 15-16, XXX, 4-5. Codoñer 1964; Palacios Royán 1978: 93-132 (texto latino) y 133-164 (traducción).

31 Así, las viudas «[...] cuando no temen que nada les frene ni están sujetas al dominio del marido, no solo van de aquí para allá ociosas, sino que lo hacen también movidas por la curiosidad y hablando de lo que no conviene hablar» (Isidoro, De Eccl. Off., XIX, 4).

${ }_{32}$ Leandro, De inst. virg., 89-91: "Suelen, en efecto, quienes se casan, aportar dotes, y entregar sus patrimonios por la pérdida de su pudor, de manera que más parecen haber comprado que tomado esposas». También incide en la pérdida de libertad y pudor de la casada en De inst. virg. 264-265, y en 282-286: (la virgen) «no se arrastra al servicio del cuerpo por el hecho de que por ley natural está sometida al varón».

33 Clark 1998: 113-115; Schroeder 2004: 432, nota 85. Y la misma idea aparece de nuevo en uno de los textos occidentales tardoantiguos más relevantes acerca del maltrato de la casada, el tratado latino Ad Gregoriam, un anónimo procedente de la península itálica, del s. V o VI d. C., cfr. Dossey 2008: 15, nota 57, y 17. Una traducción completa del tratado en Cooper 2007. mujer casada no debe ser tratada como una esclava del marido y, por tanto, corregida mediante la violencia física. ${ }^{34}$

En consecuencia, según expresa Isidoro de Sevilla, la menor virtus de la mujer explica su debilidad física y moral, que precisamente mina su posible resistencia, y facilita su sometimiento en las relaciones conyugales, en las que el principal atributo asignado al marido es la vis (fuerza). ${ }^{35}$ Por ello, en $L V$. III, 1,5 es requisito del matrimonio que la mujer sea más joven que el hombre, para tolerar mejor su dominio sobre ella, y el hombre mayor que ella, para estar en condiciones naturales de ejercer ese dominio. El discurso normativo y patrístico considera la fuerza (vis) como elemento presente necesariamente en el ejercicio del poder marital, porque es consustancial al varón. ${ }^{36}$ Esta consideración de la fuerza como atributo propio, natural y definitorio de la condición del varón, como instrumento posibilitador del ejercicio de la potestad marital y regulador de las relaciones conyugales, que encontramos tanto en el discurso normativo como patrístico hispanovisigodo, puede abrir una puerta a la posibilidad de un ejercicio de violencia directa del marido sobre la mujer en un marco de exceso de la autoridad marital, que resultaría legitimada y precisamente por la ausencia de reconocimiento del fenómeno en la legislación secular, que sí reconoce y penaliza, en cambio,

34 Schroeder 2004: 441. Precisamente el derecho imperial oriental tardorromano y el justinianeo sancionaba a los maridos que pegaban a sus mujeres con palos y flagelos, métodos propios del castigo de los esclavos, y no adecuados a la dignidad de una mujer libre, ver nota 6.

35 García Moreno 1986: 417 ya notó la incidencia del tema de la violencia del hombre en su trato sexual con las mujeres en las obras de Isidoro y Leandro. Precisamente Halperin (1990) ha defendido que las relaciones sexuales en las sociedades antiguas no eran conceptualizadas como un acto voluntario y recíproco, sino como una expresión de estatus personal y social, una expresión de dominación que implicaba cierta violencia y en la que, en el mundo clásico, no era necesariamente prevalente la coordenada heterosexual, sí, naturalmente, en las sociedades cristianas. En el discurso acerca del sexo conyugal de Isidoro y Leandro pervive esta expresión de estatus social, de dominación impositiva, pero ahora desde la coordenada de la heterosexualidad y la jerarquía de género, que sitúa al hombre como dominante/superior y a la mujer como dominada/inferior.

$36 \quad$ Gallego Franco 2003: 423 y 426-427: el marido es el administrador de la sexualidad en el matrimonio legítimo, incluso de forma impositiva. Isidoro otorga también un papel clave a la superior fuerza del varón en las propias relaciones sexuales con su mujer, que se ve así «físicamente» imposibilitada de rechazarle, pero también «moralmente», ya que no solo la vis, sino también la virtus es menor en la mujer que en el varón. Y debe entenderse ésta última como un conjunto de cualidades que conforman la fortaleza física pero también moral de la persona: valor, valentía, esfuerzo, talento, perfección moral. El mismo binomio fuerza/relación sexual también en Etymol., VIII, 11, 76: «Dicen que Venus se llama así porque una virgen solo deja de serlo cuando se recurre a la fuerza» (Venerem exinde dicunt nuncupatam, quos sine vi femina virgo esse non desinat). Este pobre concepto de la naturaleza femenina, de raíz pagana, se refuerza ahora con el papel que el cristianismo asigna a Eva en el pecado original, y así la Regula Communis (Reg. Com., XV, 487-491; Campos y Roca 1971: 199), que rige la vida monástica de la Gallaecia de la segunda mitad del s. VII d. C., afirma: «Creedme, no puede habitar sinceramente con el Señor quien se junta a cada paso con mujeres, pues por la mujer se apoderó la serpiente, es decir, el diablo, de nuestro primer padre, y, porque obedeció no al Señor, sino al diablo, sintió al instante el acicate de la carne; y por lo mismo, pues, sentimos esta pasión los hijos, y sabemos que, apresados por ella nuestros padres, fueron privados de las delicias del paraíso». Una síntesis de las negativas creencias de los Padres de la Iglesia sobre la naturaleza femenina en Anderson y Zinsser 1992: I, 101-108. 
los excesos de la autoridad dominical. Además, la norma legal ya legitima en un caso, el del adulterio de la casada, la violencia del marido sobre la mujer, al permitirle ser el brazo ejecutor de la pena de muerte con la que el delito es sancionado. ${ }^{37}$

Pero, además, la autoridad marital así concebida, no solo es un principio establecido con gran claridad y energía en la Lex Visigothorum, sino que en la norma legal alcanza el rango privilegiado de principio esencial del equilibrio social y la prosperidad de los pueblos. El análisis del proemio de $L$ V. III, 1, 5 desarrollado por Esperanza Osaba llama la atención sobre el uso que hace el legislador del término concors (concordia), un bien que producen las nupcias que cumplen las condiciones apropiadas, y del que se beneficia la progenie engendrada en su seno. Este bien puede trasladarse, además, del ámbito privado al público. En el primer libro de la Lex Visigothorum (L. V. I, 2, 6) se menciona a la concordia (concors) como una línea de conducta que confiere a los pueblos la victoria sobre sus enemigos. Concluye Osaba que el daño que causa la unión desigual es trasladado en la norma legal del ámbito privado a uno público de primer orden, puesto que la falta de concordia en las nupcias atenta contra uno de los instrumentos más importantes para la victoria del pueblo y del Estado sobre los enemigos. ${ }^{38}$ En consecuencia, la concordia que emana de las costumbres correctas se establece en la Lex Visigothorum como un principio esencial de la prosperidad y la supervivencia de los pueblos, y se comienza a construir con el respeto a las costumbres correctas en la unión conyugal que sustenta la familia como institución social básica.

\footnotetext{
$37 \quad$ La norma legal permite que el adulterio de la casada, que desafía en la forma más grave la autoridad marital, pueda ser castigado directamente por el marido ofendido. Así L. V. III, 4, 1-4 (antiquae) reconoce, con carácter general, el derecho del marido/prometido a matar a la mujer/prometida y al amante, tanto al ser sorprendidos en adulterio flagrante como fruto del resultado de un juicio, ya que el juez pone a la mujer y al amante en manos del marido ofendido. LV III, 4, 9 (antiqua) entrega a la soltera libre que hace adulterio con un hombre casado, a la mujer de éste, para que se vengue como quiera, sin excluir la pena de muerte, pero, significativamente, no reconoce a la casada ese derecho a resarcirse respecto del propio marido adúltero, porque se preserva el orden jerárquico de la unión conyugal, en el que el marido prevalece sobre la mujer. En definitiva, el delito de adulterio en la Hispania tardoantigua abandona en buena medida el ámbito público para situarse mucho más en el plano de una justicia privada y/o familiar, bien sea por la decadencia de la autoridad pública en lo que había sido el Imperio Occidental, como señala Dossey, o por una influencia de las tradiciones germánicas de venganza familiar, como apuntan otros especialistas como Jiménez Garnica, o por ambas cosas: D'Ors 2014: 144-145; Dossey 2008: 7; Jiménez Garnica 1995: 149. Acerca de esta cuestión, Dossey (2008: 12) llama la atención sobre una carta de san Agustín (Epistulae nuper in lucem prolatae, VIII) en la que señala la posible solución de una disputa familiar que implicaba a una mujer, su marido, su suegra y una esclava, y en la que muestra su concepción de las jerarquías domésticas: el hombre libre, si culpable, es golpeado una autoridad pública, la mujer por su marido pero en presencia de una autoridad pública, y la esclava por cualquier adulto libre de la familia. Obsérvese que el castigo de la mujer ya recae en la mano del marido más que en la de la autoridad pública, en el marco de la progresiva consolidación legislativa y social del concepto de autoridad marital en la tardorromanidad.

38 Osaba 2011: 134-136 y 138, es el propio rey el que se propone cumplir con su deber e imponer mediante la ley las correctas costumbres, que procuran la concordia entre los ciudadanos y coadyuvan al
} triunfo sobre los enemigos (L. V.I, 2, 6).
Dicho de otro modo, el respeto a los requisitos de igualdad de linaje de los cónyuges y mayor edad del marido en el establecimiento del matrimonio asegura el adecuado ejercicio de la autoridad marital, en la que la vis es elemento fundamental, y la posición subordinada de la casada. Ello garantiza la concordia familiar y, por extensión, la concordia social. La concordia conyugal es considerada así una parte más de la concordia social. ${ }^{39}$ Esto explica que en el discurso legal y patrístico hispanovisigodo predomine la subversión del orden conyugal como el efecto principal de unas nupcias que no respeten las debidas formalidades, junto con el envilecimiento de la progenie, y no se contemplen otros posibles efectos negativos, como la violencia marital a la que se refiere Crisóstomo. ${ }^{40}$ Por ende, el mismo Isidoro utiliza en De Ecclesiasticis Officiis la perspectiva de la norma legal, y traslada la desobediencia de la casada del ámbito privado al espacio público, constituido ahora por la comunidad cristiana, al señalar que el varón es cabeza de la mujer como Cristo lo es de la Iglesia, y que la mujer debe seguir a su cabeza como la Iglesia sigue a Cristo (De Eccl. Off., XX, 13). En la misma obra (De Eccl. Off., XX, 14) incide en esta línea de pensamiento apuntando que el varón es la cabeza de la mujer como Cristo lo es del varón, de manera que toda mujer que no esté sujeta a su marido es culpable del mismo delito que el varón que no se somete a Cristo. ${ }^{41}$ Resulta, por tanto, que el marido tiene un solo señor, Cristo, mientras que la casada tiene dos, su marido y Cristo, y equipara la desobediencia de la mujer al marido nada menos que con la desobediencia del marido a Dios. Cuando Isidoro explica el ceremonial del matrimonio cristiano en De Ecclesiasticis Officiis expone razonadamente que todo en él simboliza el sometimiento de la mujer al varón. ${ }^{42}$

Es así como la autoridad marital, la sujeción de las casadas a sus maridos, se convierte en ley natural, cuestión de Estado y mandato divino, expuesto en palabras de san Isidoro:

$39 \quad$ Schroeder (2004: 440-442) se refiere a la tradición en la patrística griega y latina de este concepto de la concordia conyugal, para los Padres de Occidente mantenida por el marido a través de las amenazas y la aplicación del castigo físico, mientras que para otros, como Crisóstomo, es la ira y la violencia de los maridos la que rompe la concordia conyugal, haciendo últimos responsables a éstos, y no a sus mujeres, de la paz doméstica.

40 Osaba 2011: 130-132 y 140. Isidoro, De Eccl. Off., XX, 14. Sobre el envilecimiento de la progenie, L. V. III, 1, 2; Isidoro, De origine Gothorum, 37, 1-12 (= Historia Gothorum, 37, 1-16), también Gallego Franco 2004: 219-220.

41 Esta idea se sustenta igualmente en una amplia tradición patrística anterior, que parte del código doméstico neotestamentario de Efesios 5,22-6,9, y que aconseja no reducir estas prescripciones sobre el orden doméstico de género al ámbito exclusivamente privado, Menéndez Antuña 2007: 100, nota 156. De forma relevante Crisóstomo usa también la díada Cristo/Iglesia para representar la de marido y mujer, incidiendo que la casada que resiste al marido es como el que resiste a las autoridades y a lo que Dios ha ordenado y es llevado a juicio, cfr. Schroeder 2004: 429.

42 García Moreno 1986: 415-417; Jiménez Garnica 1995: 128 $129,136-137$ y 139-141. Muy explícito también Isidoro en Sententiae, 1.1, c. 11,5 y 6 : «El varón fue creado a imagen de Dios, la mujer fue formada a semejanza del varón, por lo cual le debe sujeción por la ley de la naturaleza. Asimismo, el varón ha sido creado por causa de sí mismo; la mujer para ayuda del varón» (Vir ad imaginem Dei factus est, mulier ad imaginem viri formata est; unde et illi lege naturae suniecta est. Item vir propter semetipsum factus est, mulier ob adiutorium viri creata est). 
Blasfema contra la Palabra del Señor o menosprecia el primer precepto dado por Dios y lo estima en nada; o se aparta del Evangelio de Cristo, al mismo tiempo que se aparta de la ley y de lo que pide la naturaleza, aquella que, siendo cristiana y sujeta a la ley de Dios, desea tomar precedencia a su esposo, cuando incluso las mujeres de los pueblos gentiles respetan a sus maridos por la ley común de la naturaleza. Se guarda la ley de la naturaleza, cuando, al mismo tiempo, la mujer está sujeta a Dios y a su marido. Por el contrario, si ella quiere dominar al marido, no sólo pervierte el orden de la naturaleza, sino que su hogar será tenido por miserable y perverso (De Eccl. Off., XX, 15).

En estos términos, resulta evidente la enorme presión que el discurso del poder oficial ejercía sobre las mujeres, y las casadas en particular, una presión que constituye un indudable elemento de violencia estructural, al elevar el daño causado por la desobediencia conyugal femenina a perjuicio grave para el total de la comunidad, tanto civil como religiosa, convirtiendo a la casada desobediente en una amenaza social, situando su comportamiento en la esfera del interés y la reprobación públicos. ${ }^{43}$ De hecho, la aceptación de la sumisión al marido y de la superioridad masculina constituyen condiciones reconocidas para que las casadas puedan obtener dignidad y reconocimiento social en la Antigüedad tardía. ${ }^{44}$ Finalmente, cabe preguntarse desde la investigación histórica, si en el contexto de este discurso legal y patrístico, el exceso de vis en el ejercicio de la autoridad del marido (la violencia marital), no recibiría la consideración de un mal menor comparado con el mayor de la ruptura de la concordia social. Aquí puede residir la explicación de la ignorancia de la norma legal respecto a un reconocimiento específico de la violencia marital, si bien sus efectos más graves es posible que pudieran ser denunciados por las víctimas sobre la base de la legislación que, de forma general, penaliza la violencia ejercida sobre hombres y mujeres por un tercero. ${ }^{45}$

Un excelente testimonio del funcionamiento concreto de los instrumentos del Estado para el mantenimiento de la concordia social en relación a la subversión del orden de género en las nupcias lo tenemos en La vida de San Fructuoso de Braga (s. VII d. C.). Allí se relata la ruptura del compromiso matrimonial entre un gardingo del rey y la virgen aristocrática Benedicta, por deseo de la prometida de

$43 \quad$ La Lex Visigothorum dispensa un trato muy duro a aquellas conductas femeninas que subvierten el orden de género en el matrimonio y atentan contra la autoridad marital. Es el caso de la unión de una mujer libre con su propio siervo o liberto (L. V. III, 2, 2 antiqua), que contradice el orden «natural» del matrimonio, en el que el marido prevalece sobre la mujer, y es penada con la muerte en la hoguera. Significativamente, la norma legal no se ocupa del hombre libre que se une a su sierva o liberta, situación que, conociendo el funcionamiento cotidiano de la sociedad de la época, debía ser absolutamente habitual y resulta tolerado. A la extrema dureza de la represión del adulterio de la casada y la prometida ya nos hemos referido en la nota 37.

$44 \quad$ Núñez de Paz (2015: 371, 378 y 380-381) describe cómo, a lo largo de la tardorromanidad, el discurso legal y patrístico había venido reformulando el modelo de matrona respetable diseñado en el Alto Imperio, configurándose una nueva "autoridad» femenina centrada exclusivamente en las buenas costumbres, pero sin ninguna autonomía en el ámbito familiar y negocial, volviéndose a poner el acento en las incapacidades naturales femeninas y en el principio de exclusión de las mujeres de las funciones civiles y públicas.

45 L. V. VI, 4. abrazar la vida ascética. Al ser considerada normativamente como delito (L. V. III,1,2 y 3) la ruptura del compromiso nupcial sin justificación legalmente aceptada, el gardingo presentó una demanda contra Benedicta ante el monarca, que produjo el consiguiente nombramiento de un juez de la corte, el comes Angelate, para que emitiera un veredicto legal sobre el asunto; este se desplazó hasta el monasterio, investido de la autoridad del rey (regia procinctus auctoritate), para interrogar a la denunciada en presencia del prometido abandonado, la cual fue sacada para ello del edificio «no sin violencia» (quae quum violenter fuisset egressa). ${ }^{46}$ La ruptura del compromiso, penada legalmente, hace peligrar la concordia, desde el punto de vista social, en relación a los intereses socio-políticos y económicos implicados en el proyecto de enlace, pero también desde el punto de vista del género, por la decisión libre, a priori inadmisible, de la mujer.

La Lex Visigothorum hace también el divorcio muy difícil, a la vista de las escasas razones legales admitidas para la ruptura matrimonial: el adulterio de la casada en el caso del marido, y, en el caso de la mujer, la sodomía del marido o que este le haya obligado a tener relaciones con otro hombre. ${ }^{47}$ Obsérvese que el marido que transgrede las leyes contra el divorcio es castigado por los poderes públicos, mientras que la mujer que lo hace es castigada, a instancia de los poderes públicos, por su propio marido, lo que vuelve a consagrar el principio de la subordinación de la casada, que además, en este caso, faculta al marido para aplicar una

\footnotetext{
$46 \quad$ Vita Fructuosi, 15, 25-31; Díaz y Díaz 1974.
}

47 El único motivo reconocido al marido para repudiar a su mujer es el adulterio de ésta, pero no se le permite contraer un nuevo matrimonio en tanto ella esté viva ( $L$. V. III, 6, 2). La casada únicamente puede separarse del marido, e incluso contraer un nuevo matrimonio, cuando este es reo de delitos de extrema gravedad que comprometen su naturaleza masculina o su autoridad sobre la mujer: ser sodomita u obligar a su mujer a fornicar con otro hombre (L. V. III, 6, 2 de Chindasvinto). En un primer momento la Iglesia occidental tardorromana solía permitir al marido que abandonaba a la esposa adúltera volver a casarse, pero no a la esposa que se separaba de un marido adúltero, e incluso se obligaba a ésta a volver a recibir a su marido si había fornicado con una mujer soltera, ya que ello no era adulterio; sí lo era si la que fornicaba con un hombre soltero era la casada, $c f r$. Sotomayor 2002: 72-78; Concilio de Elvira c. 8 y 9 . Sin embargo, la tendencia legislativa de la Hispania tardoantigua es a considerar el matrimonio como indisoluble, y, por tanto, negar a los separados la posibilidad de otras nupcias. Con carácter general, la legislación aplica a la mujer separada que toma un nuevo marido la misma pena que a la adúltera, y es puesta, junto a su segundo marido, en poder del primero para que haga con ellos lo que quiera, lo que no excluye la muerte (L. V. III, 6, 1 antiqua). Del mismo modo, la mujer que se casa con un hombre sabiendo que tiene una mujer anterior, tiene que ser puesta en manos de ésta para que haga con ella lo que quiera, pero aquí sí se excluye explícitamente la muerte (L. V. III, 6, 2), lo que casi equipara esta ley a la otra sobre la adúltera libre y soltera que vimos (nota 37). Las penas que se imponen al marido que deja a su mujer de forma injustificada se van agravando, pues en época de Leovigildo tiene que devolver a ésta todos sus bienes, recibidos por cualquier vía (L. V. III, 6, 1 antiqua), mientras que un siglo más tarde Chindasvinto añade a las sanciones patrimoniales la recepción de azotes públicos, la decalvación y el exilio, o incluso la pérdida de libertad por voluntad del rey. La mujer que quiere separarse sin motivo también es castigada, pero no por la autoridad pública, sino por el marido, en cuyas manos es puesta por la autoridad pública junto con todo su patrimonio (L. V. III, 6, 2). Finalmente $L$. V. III, 6, 3 (de Recesvinto) extiende idéntico tratamiento penal a la ruptura de los esponsales o compromiso matrimonial. 
violencia física legítima sobre su mujer. ${ }^{48}$ El divorcio no era, por tanto, un instrumento que pudiera prestar una protección a las mujeres hispanovisigodas frente a los excesos de la autoridad marital o los vicios de maridos poco virtuosos (adúlteros, borrachos, pródigos, maltratadores...). Por el contrario, el triunfo de la concepción cristiana del matrimonio indisoluble ha venido siendo valorado por los especialistas como un factor que propició socialmente el maltrato o la postergación de la casada, como vía de salida a la frustración de un marido descontento. ${ }^{49}$ Nótese, también, que la muerte de la adúltera deja libre del lazo matrimonial al marido ofendido, legitimado legalmente para ejecutarla, y en posesión de todo el patrimonio de la mujer infiel. ${ }^{50}$

Por su parte, los cánones conciliares de la Hispania tardorromana y visigoda ignoran por completo, como la legislación secular, el fenómeno de la violencia marital, si bien tampoco prestan gran atención al régimen de vida conyugal, más allá de los pecados de adulterio y aborto. Sin embargo, las autoridades eclesiásticas establecieron muy tempranamente y de forma clara el principio de sujeción de la casada a su marido en los cánones conciliares. Ya el Concilio de Elvira, a comienzos del s. IV d. C., en su canon 81 señala que la casada no puede escribir a seglares en nombre propio, sino en el de su marido, y no puede recibir cartas de amistad de ninguno dirigidas a ella sola, a lo que el canon 1 del primer Concilio de Zaragoza (380 d. C.) añade que la casada no puede recibir lecciones de otro hombre que no sea su marido. ${ }^{51}$ La legislación canónica coincide con el legislador civil en depositar en manos del marido el castigo/corrección de la casada adúltera, legitimando en este caso el uso de la violencia marital. Ello ocurre en el canon 7 del primer Concilio de Toledo (397-400 d. C.), que concede al clérigo, en tanto que marido, potestad para aplicar la pena a su mujer si ha cometido adulterio, pena que consiste en obligarla a hacer penitencia, auque sea por la fuerza, recluyéndola y atán-

48 Wemple 1981: 42, en relación a la sociedad franca merovingia y carolingia, subraya la enorme dificultad de las mujeres para divorciarse en las leyes germánicas; señala que si la mujer era adúltera el marido podía divorciarse sin obligaciones y tenía el derecho a matarla a ella y a su amante si les sorprendía en adulterio flagrante. No es de extrañar, como recuerda Wemple, que la reina Fredegunda de Neustria hiciera asesinar a su marido Chilperico I (584 d. C.) cuando este empezó a sospechar de un posible adulterio de ella (Greg. Tours, Hist. Franc., 35).

49 Wemple 1981: 97 y 104. Sobre la indisolubilidad del matrimonio cristiano, cfr. Lamberigts 2014: 378; Churruca 1998: 11-34. Isidoro de Sevilla se preocupa, por su parte, de reivindicar la indisolubilidad del matrimonio cristiano en el capítulo veinte de Los Oficicios Eclesiásticos (De Eccl. Off., XX, 10 y 11), en el que plasma de forma detallada su concepción del mismo y de la convivencia conyugal. Sin embargo admite la posibilidad de repudiar a la mujer adúltera, aunque establece como mandamiento de la Iglesia la mutua fidelidad de los cónyuges, frente al derecho público que solo considera adúltera a la mujer ( $D e$ Eccl. Off., XX, 12). En la misma linea va la legislación conciliar, cfr. Concilio de Toledo XII (681 d. C.) canon 8, que no permite divorciarse de la mujer de uno, salvo en caso de fornicación (adulterio).

50 Las mujeres de alto rango social podían acumular importantes patrimonios propios en la Hispania tardoantigua por distintas vías: dote marital, obsequios y donaciones recibidos de sus padres o de su marido, tanto en vida como por testamento, el ejercicio de sus derechos de herencia familiar, tanto testada como intestada, donaciones del monarca, Gallego Franco 2005: 342.

51 Aunque la motivación pudiera ser evitar la heterodoxia, y no la infidelidad, lo cierto es que se subraya la sujeción al marido, Fernández Ubiña 2005: 285-286; Gallego Franco 1998: 237-245 y 2013: 110. dola en la casa, para evitar su huída. ${ }^{52} \mathrm{~A}$ pesar de la dureza del trato recibido, siendo las mujeres encerradas en la casa por la fuerza, incluso atadas si fuera necesario, y obligadas a severos ayunos mientras siguen asumiendo las tareas domésticas en el caso de los clérigos pobres que no pueden permitirse tener servidumbre, el canon resulta más benevolente que la legislación civil, que, como hemos visto, permitía a los maridos aplicar a las mujeres adúlteras la pena de muerte, que aquí se excluye expresamente. ${ }^{53}$

Resulta llamativo que, también tempranamente, los cánones conciliares hispanos tardorromanos se ocupen de los excesos de la autoridad de los dueños sobre los esclavos, en concreto de las dueñas, situando a las mujeres como como actores de violencia física en el ámbito doméstico. ${ }^{54} \mathrm{El}$ canon 5 del Concilio de Elvira, Si domina per zelum ancillam occiderit, considera a algunas matronas cristianas capaces de maltratar a una esclava con tanta violencia como para causarle la muerte, y que el motivo de ello eran los celos: «Si una mujer, enardecida por el furor de los celos, azota a su esclava hasta el punto de que en el término de tres días exhala su alma entre grandes dolores....". ${ }^{55}$ Es muy posible que los celos a los que el canon se refiere sean los causados por la sospecha de la infidelidad del marido con la esclava en cuestión, dado que es bien conocido que el uso sexual de las esclavas por parte de los dueños fue un hábito social y doméstico común en la Antigüedad. ${ }^{56}$ Sin embargo, la

52 VII. Que el clérigo cuya mujer pecare, tenga potestad de castigarla sin causarle la muerte, y que no se siente con ella a la mesa. Se tuvo por bien que si las mujeres de los clérigos pecaren con alguno, para que en adelante no puedan pecar más, sus maridos puedan, sin causarles la muerte, recluirlas y atarlas en su casa, obligándolas a ayunos saludables, no mortales, de tal modo que los clérigos pobres se ayuden mutuamente si acaso carecen de servidumbre, pero con las esposas mismas que pecaron, no tomen ni tan siquiera el alimento a no ser que, hecha penitencia, vuelvan al temor de Dios. Vives 1963: 21-22.

53 La Iglesia hispana tendió a calificar de adulterio las infidelidades tanto de los maridos como de las mujeres, de manera que las penas canónicas por este delito afectaban a unos y a otras, aunque con mayor gravedad a las mujeres, debido a los condicionantes de género, así ya en el Concilio de Elvira, Fernández Ubiña 2005: 303-307. No consideraban la pena de muerte, aunque sí dilatados años de penitencia, con la marginación social que eso suponía: los textos de la época insisten en la separación de la comunidad y la identificación pública a través de signos claros (tonsura, vestimenta) del penitente. Concilio de Braga II (572 d. C.), c. LXXVI; Gallego Franco 2013: 106 y nota 69.

54 Schroeder (2004: 422-423) y Dossey (2008: 9) se refieren también a esta violencia doméstica ejercida por mujeres, siendo las víctimas en este caso los niños y las esclavas.

55 Si qua femina furore zeli accensa flagris verberaverit ancillam suam ita ut intra tertium diem animam cum cruciatu effundat, eo quod incertum sit voluntate an casu occiderit, si voluntate, post septem annos; si casu, post quinquennii temora acta legitima paenitentia ad communonem placuit admitti. Quod si infra tempora constituta fuerit infirmata, accipiat communionem. "Si una mujer, enardecida por el furor de los celos, azota a su esclava hasta el punto de que en el término de tres días exhala su alma entre grandes dolores, al no existir seguridad de que la muerte haya sido intencionada o casual, se acordó que sea admitida a la comunión después de haber cumplido la penitencia establecida: si la muerte fue intencionada, al cabo de siete años; si fue casual, por un período de cinco años. No obstante, si llega a enfermar durante el tiempo señalado, reciba la comunión». Sotomayor y Fernández Ubiña 2005: 22 y 39-40.

${ }_{56}$ Esta circunstancia no debía resultar absolutamente extraña en la vida cotidiana, y por ello mereció un canon en el Concilio. Señala Fernández Ubiña (2005: 277) que los Padres trataron el caso particular de aquella ama porque alguno de los presentes planteó este pro- 
sociedad occidental tardoantigua esperaba que las casadas toleraran en silencio las infidelidades de sus maridos, bien con esclavas, prostitutas u otras mujeres. Hemos visto que la Lex Visigothorum contempla el adulterio como causa de separación del matrimonio solo en el caso de la mujer adúltera y no al contrario, en sintonía con los cánones conciliares hispanos que llegan a pedir a la casada cristiana recibir al marido adúltero de nuevo en casa. ${ }^{57}$ Esta exigencia de silencio, unida a la propia infidelidad del marido, podía generar en la casada una intensa frustración y disgusto que no sería extraño que en ocasiones se tradujera en el castigo violento y cruel de la esclava sospechosa. El propio Leandro en De institutione virginum, enumerando los muchos padecimientos de las mujeres casadas en su afán de enaltecer la opción de la virginidad consagrada, se refiere explícitamente al dolor causado por las infidelidades de los maridos. ${ }^{58}$ Resulta, sin duda, de gran singularidad e interés este canon 5 en el contexto del Concilio de Elvira ${ }^{59}$, que cobra su completa dimensión en la esfera de las relaciones jerárquicas de la familia en la Hispania tardoantigua y de la violencia psicológica y física que éstas pueden generar. ${ }^{60}$

blema en la asamblea, y que los cánones iliberritanos son de carácter casuístico. Pero también señala que analizaban problemas concretos de las comunidades de Hispania, problemas de la vida cotidiana. Es posible que este canon esté motivado por un hecho concreto, y que los presentes tuvieran en mente a una «dueña» con nombre propio, pero que el hecho que inspirara el canon fuera concreto no implica necerariamente que fuera excepcional. Considero razonable pensar que los presentes plantearan a los Padres sobre todo consultas sobre aquellos problemas generados por comportamientos transgresores de la fe que preocupaban a la comunidad por resultar comunes o producirse con relativa frecuencia. Y a diferencia de Fernández Ubiña (2005: 285) considero que el adulterio del marido es la causa más probable de los celos de la dueña, teniendo en cuenta lo que conocemos de la vida conyugal del momento.

57 Concilio de Elvira c. 8, 9, 47 y 64. Concilio de Toledo VIII, c. 2; Concilio de Toledo XII, c. 8. Gallego Franco 1991: 141-142. Ello no es incompatible con el hecho de que el discurso canónico y patrístico hispano exija fidelidad por igual a ambos cónyuges (cfr. notas 49 y 53 y Fernández Ubiña 2005: 303-304). Dossey 2008: 22-23, explorando las vidas de santos tardoantiguas, señala como una cicunstancia no extraña las críticas de las mujeres a los asuntos amorosos de sus maridos con esclavas domésticas y la reacción violenta de éstos ante estas interferencias. Clark (2015: 61) señala que según san Agustín, su madre Mónica escapó a la experiencia común de la violencia doméstica de las casadas de Tagaste por su tacto en manejar los enfados de su marido, y porque soportó sus infidelidades sin quejarse. Hillner (2015: 162-163) se refiere también a situaciones reales recogidas en papiros egipcios del s. IV d. C. de mujeres maltratadas seriamente por sus maridos por oponerse a sus infidelidades, confictos que mediadores civiles o eclesiásticos intentaban resolver con la receta del aguante o paciencia de la casada.

58 Leandro, De inst. virg., 326-371. Aunque Leandro carga las tintas en los aspectos más negros de la vida de la casada en su enfoque apologético de la virginidad, no cabe duda de que es muy significativo que se refiera explícitamente a las infidelidades de los maridos entre los sufrimientos habituales de las mujeres en el matrimonio.

59 Gallego Franco 1991: 142-143 y 1998: 241-242.

60 Hijos, esposas y esclavos pueden resultar afectados por el maltrato en el marco de las relaciones jerárquicas de la familia tardorromana y tardoantigua, Birulés 2007: 17-25; Pedregal 2015: 270; Schroeder 2004: 432-433; Shaw 1987: 3-51. En relación al maltrato de la progenie, obsérvese que la legislación visigoda, en el caso de segundas nupcias del padre viudo, sugiere la posibilidad de que los hijos/ as puedan sufrir algún tipo de maltrato moral o físico por parte de la madrastra. En el Código de Eurico, véase CE 321 sobre la herencia de los bienes maternos o bona materna: «El que contrajo nuevas nupcias,
En conclusión, el discurso legal, secular y canónico, y el de la patrística de la Hispania tardoantigua se sitúan plenamente en el fondo común de conceptos y creencias respecto a la autoridad marital y la sumisión de la casada propio del Occidente cristiano tardorromano y tardoantiguo. Asienta de forma inequívoca el principio de la autoridad marital y la sujeción de las casadas a sus maridos, pero es muy parco en el establecimiento de límites para la misma (el único relevante es prostituir a la propia mujer), obviando además la penalización de posibles abusos violentos en su ejercicio, que sí contempla en el caso del ejercicio de la potestad de los dueños sobre los siervos. Legitima el uso de la violencia severa sobre las casadas por parte de los maridos en relación al castigo de la infidelidad femenina. Considera que la fuerza (vis) es un elemento y un instrumento natural propio de la masculinidad en el ejercicio de la potestad marital y en su deber y derecho de corrección de la casada. Las uniones conyugales no deben poner en entredicho la capacidad del varón para ejercer esa fuerza/vis sobre la mujer, caso de los matrimonios en los que ésta es de mayor edad que el marido o hay desigualdad de rango entre los cónyuges. Además, hace de la autoridad marital un principio establecido por la naturaleza y la divinidad, un principio de primer orden de importancia social, ya que resulta necesario para el equilibrio y prosperidad de la sociedad civil y la comunidad cristiana (la Iglesia). Sin embargo, este discurso ignora los posibles excesos del ejercicio de la autoridad marital y la violencia que puedan generar sobre las mujeres, mientras que sí es bien consciente de las transgresiones femeninas hacia la autoridad del marido y las denuncia, critica y penaliza convenientemente (adulterio, falta de respeto al marido, querer tomar precedencia sobre él).

La presencia de la retórica de la fuerza en relación a la autoridad marital en el discurso normativo y patrístico hispanovisigodo revela la existencia de un marco de violencia estructural sobre las mujeres casadas, que en ocasiones podía devenir en un ejercicio de violencia directa sobre éstas por parte de sus maridos. A pesar de ello, apenas se registran en las fuentes de la Hispania tardoantigua casos concretos de violencia marital, como sí recogen las fuentes en otros contextos territoriales de la Antigüedad tardía. ${ }^{61}$ Posiblemente ello se deba a que este podía ser un comportamiento masculino socialmente tolerado en la aplicación cotidiana del ejercicio de la autoridad marital, acciones invisibles para la sensibilidad de los observadores de la época, salvo en casos de violencia extrema. ${ }^{62}$ Hay que sumar ade-

devuelva luego todos los bienes maternos a los hijos, para que, al pasar a una casa extraña con sus cosas, no sean injuriosamente vejados por la madrastra (novercae suae vexentur iniuriis)»; L. V. IV, 2, 13 contempla en estos casos la posibilidad del nombramiento de un tutor para los hijos/as, en previsión de problemas con la madrastra, quien será nombrado por un juez y será el pariente más próximo de la mujer difunta, cfr. D’Ors 2014: 257; Gallego Franco 2009: 315 y 319.

61 En otro ámbitos de la Europa Occidental tardoantigua las fuentes recojen casos concretos explícitos y bastante detallados del maltrato de la casada, por ejemplo en el reino Franco o en el ámbito itálico, cfr. Cooper 2007: 143-198; Wemple 1981: 43, 84-86 y 103-104. También en el Egipto tardoantiguo, Urbanik 2013: 270-272.

62 Segura Graíño 2008: 35-36. Contamos con algunas referencias a episodios de violencia marital en textos de carácter históriográfico referidos a los matrimonios regios visigodos que creemos merecen un análisis y valoración en detalle: Gallego Franco (en prensa). 
más los efectos de la «cultura del silencio» que, en torno a estos episodios de maltrato, se percibe ya en otras fuentes textuales tardorromanas de Occidente, muy expresivamente, por ejemplo, en Las Confesiones de san Agustín. ${ }^{63}$

En última instancia, el gran ausente en el discurso normativo y patrístico estudiado aquí es el amor cristiano, conformador decisivo de los primeros códigos de convivencia conyugal en textos relevantes de las primeras comunidades cristianas, como son los códigos domésticos neotestamentarios. Son pasajes en los que se fijan los deberes recíprocos de los miembros de una casa, confirmando las relaciones jerárquicas patriarcales propias de la familia grecorromana, y en concreto la sumisión de la casada al marido, pero transformándolas desde una clave cristiana. En la coordenada de convivencia conyugal responden al esquema básico mujeres, sed sumisas a los maridos, maridos, amad a las mujeres. En los más antiguos de estos, como el de Colosenses, puede interpretarse que es la entrega recíproca de los cónyuges, sustentada en el amor cristiano y la fe, la que distingue a la familia cristiana de la pagana. Esta entrega redime la situación de sumisión de la mujer, que, no obstante, no es discutida, y conjura el comportamiento agresivo del marido hacia ella, cuya realidad es implícitamente reconocida. Esta propuesta, sin contradecir el orden de género vigente, quería ofrecer un nuevo modelo de convivencia conyugal, y permea la perspectiva respecto a la convivencia conyugal de autoridades eclesiásticas tan relevantes como Juan Crisóstomo. Sin embargo, este modelo fue disipándose al compás del proceso posterior de institucionalización y ordenamiento de la Iglesia y de su hermanamiento con el poder público y político; además de la propia carga misógina de las influencias judeo-orientales del cristianismo, todo este proceso se desarrolló en un fondo sociocultural tardorromano que, en lo general, asumía como valores de género naturales e inmutables aquellos que conducían al menosprecio y la discriminación de las mujeres. ${ }^{64}$ El discurso normativo y patrístico de la Hispania tardoantigua sobre la autoridad marital y su relación con la vis (fuerza) constituye un buen exponente del resultado final de este proceso.

\section{BiBLIOgRAFÍA}

Alfaro Bench, V. 2015. «El honor y la vergüenza como valores culturales decisivos en la díada mujer-marido de la Epístola a los Colosenses». Euphroyne nova serie vol. XLIII: 47-67.

Anderson, B. S. y Zinsser, J. P. 1992. Historia de las mujeres: una historia propia. Barcelona: Crítica.

Arjava, A. 1996. Women and Law in Late Antiquity. New York: Clarendon Press.

Beaucamp, J. 1990. Le statut de la femme à Byzance (4e-7e siècles). I. Le droit imperial. Paris: De Boccard.

Birulés, F. 2007. "Reflexiones sobre la vulnerabilidad y la violencia», en D. Molas (ed.), Violencia deliberada. Las raíces de la violencia patriarcal: 17-25. Barcelona: Icaria.

Bonfante, G. 1987. «Vir et vis». RAL 41: 197-198.

63 Clark 1998: 114; Schroeder 2004: 432.

64 Colosenses 3, 18-19: «Mujeres, sed sumisas a vuestros maridos, como conviene en el Señor. Maridos amad a vuestras mujeres, y no seáis ásperos con ellas». Alfaro Bench 2015: 47-67; Durán Mañas 2016: 176-177; Rivas Rebaque 2002: 396-397. También Fernández Ubiña 2005: 313-314 y 321.
Brown, P. 1992. Power and Persuasion in Late Antiquity. Madison: University of Wisconsin Press.

Campos, J. y Roca, I. 1971. Santos Padres Españoles. II. San Leandro, San Fructuoso y San Isidoro. Reglas monásticas de la España visigoda. Los tres libros de las "Sentencias». Madrid: Biblioteca de Autores Cristianos.

Churruca, J. de. 1998. "La unidad de la carne en algunas concepciones del matrimonio en el cristianismo primitivo", en J. Mangas y J. Alvar (coords.), Homenaje a Jose Mạ Blázquez, vol. 6: 11-34. Madrid: Ediciones Clásicas.

Clark, G. 2006. «Desires of the Hangman: Augustine on Legitimized Violence», en H. A. Drake (ed.), Violence in Late Antiquity. Perceptions and Practices: 137-146. Santa Barbara: University of California, Ashgate Ed.

Clark, G. 2015. Monica. An ordinary saint. Oxford: Oxford U. P.

Clark, P. 1998. "Women, Slaves and the Hierarchies of Domestic Violence», en S. R. Joshel y S. Murnaghan (eds.), Women and Slaves in Greco-Roman Culture: 109-129. London: Routledge.

Codoñer, C. 1964. El "De viris illustribus» de Isidoro de Sevilla. Salamanca: CSIC.

Cooper, K. 2007. The Fall of the Roman Household. Cambridge: Cambridge University Press.

D’Ors, A. 2014. El Código de Eurico. Madrid: Boletín Oficial del Estado.

De Bruyn, Th. S. 1999. «Flogging a Son: The Emergence of the pater flagellans in Latin Christian Discourse». Journal of Early Christian Studies 7 (2): 249-290.

Díaz y Díaz, M. A. 1974. La vida de San Fructuoso de Braga. Braga.

Dossey, L. 2008. "Wife Beating and Manliness in Late Antiquity». Past and Present 199 (may): 3-40.

Durán Mañas, M. 2016. "La mujer en las Epístolas de San Pablo», en M. López Salvá, I. Sanz Extremeño y P. de Paz Amérigo (eds.), Los orígenes del cristianismo en la literatura, el arte y la filosofía (I): 157-179. Madrid: Clásicos Dykinson.

Evans-Grubbs, J. 1993. "Constantine and Imperial Legislation on the Family", en J. Harries e I. Woods (eds.), The Theodosian Code: 120142. London: Cornell University Press.

Fernández Ubiña, J. 2005. «Mujer y matrimonio en el concilio de Elvira», en M. Sotomayor y J. Fernández Ubiña (coords.), El concilio de Elvira y su tiempo: 275-322. Granada: Public. Universidad de Granada.

Gallego Franco, H. (En prensa). "Política y violencia de género en Hispania tardoantigua. Los matrimonios regios visigodos». Colección Instrumenta-CEIPAC/Universidad de Barcelona y Editorial UFPRUniversidade Federal do Paraná (Brasil).

Gallego Franco, H. 1991. Femina Dignissima. Mujer y Sociedad en Hispania Antigua. Valladolid.

Gallego Franco, H. 1998. «La cuestión femenina en el primitivo cristianismo hispano: a propósito de los cánones $\mathrm{V}, \mathrm{XXXV}$ y LXXXI del Concilio de Elvira». Helmantica XLIX, 150: 237-245.

Gallego Franco, H. 2002. «Legislación y sexualidad en la Hispania Visigoda», en L. Hernández Guerra y J. Alvar (eds.), Jerarquías religiosas y control social en el mundo antiguo (Actas del XXVII Congreso Internacional GIREA-ARYS IX): 611-625. Valladolid: Publicaciones Uva.

Gallego Franco, H. 2003. "La sexualidad en las Etimologías de San Isidoro de Sevilla. Cristianismo y mentalidad social en la Hispania visigoda». Hispania Sacra 55: 407-432.

Gallego Franco, H. 2004. "Modelos femeninos en la historiografía hispana tardoantigua. De Orosio a Isidoro de Sevilla». HAnt XXVIII: 197-222.

Gallego Franco, H. 2005. "Imágenes de mujeres en el ocaso de una cultura», en I. Morant (dir.), Historia de las mujeres en España y América Latina. Vol. I. De la Prehistoria a la Edad Media: 337-367. Madrid: Cátedra.

Gallego Franco, H. 2009. "Madre y maternidad en el ordenamiento jurídico de la Hispania tardoantigua (siglos V-VII d. C)», en R. M. a Cid López (coord.), Madres y maternidades. Construcciones culturales en la civilización clásica: 293-325. Oviedo: KRK Ediciones. 
Gallego Franco, H. 2010. «Los márgenes de la maternidad en el universo jurídico tardorromano del Codex Theodosianus", en R. M.a Cid López (coord.), Maternidad/es: representaciones y realidad social. Edades Antigua y Media (Colección Laya no 31): 233-250. Sevilla: Ed. Al-Mudayna.

Gallego Franco, H. 2013. «lluminando sombras: mujeres y parámetros de marginación social en Hispania tardoantigua», en R. González Salinero (ed.), Marginados sociales y religiosos en la Hispania tardorromana y visigoda: 85-117. Madrid-Salamanca: Signifer.

García Herrero, G. 1991. "Julián de Toledo y la realeza visigoda», en Arte, sociedad, economía y religión durante el Bajo Imperio y la Antigüedad Tardía. Antigüedad y Cristianismo VIII: 201-256.

García Iglesias, L. 1976. "La edad difícil y la sexualidad adolescente en la España visigoda». Hispania Antiqua VI: 79-96.

García Moreno, L. A. 1986. «La mujer visigoda entre la represión sexual y el poder político», en Actas de las V Jornadas de Investigación Interdisciplinaria: La mujer en el mundo antiguo: 415-426. Madrid: SEM/UAM.

González Mínguez, C. 2008. "Sobre historia de las mujeres y violencia de género». Clio \& Crimen: La violencia de género en la Edad Media 5: 14-23.

Halperin, D. 1990. One Hundred Years of Homosexuality and Other Essays on Greek Love. London: Routledge.

Hillner, J. 2015. Prison, Punisment and Penance in Late Antiquity. Cambridge: Cambridge U. P.

Jiménez Garnica, A. 1995. "La mujer en el mundo visigodo», en M. a D. Verdejo (coord.), Comportamientos antagónicos de las mujeres en el mundo antiguo: 127-160. Málaga: Public. Universidad de Málaga.

Jiménez, F. y Muñoz, F. 2004. «Violencia directa», en M. López (dir.) Enciclopedia de la Paz y Conflictos: 1161-1168. Granada: Eirene.

Lamberigts, M. 2014. «Agustín sobre el matrimonio. Una comparación del De bono coniugali y De nuptiis et concupiscentia», Augustinus LIX, 234-235 (julio-diciembre): 368-389.

Lex Visigothorum o Liber Iudicum/El Fuero Juzgo, Los códigos españoles comcordados y anotados. 1847. Madrid: Imprenta La Publicidad.

McDonnell, M. 2006. Roman Manliness. Virtus and the Roman Republic. Cambridge: Cambridge University Press.

Menéndez Antuña, L. 2007. Mujer y poder en el Cristianismo antiguo. Las luchas de poder en las comunidades cristianas del siglo I. Un acercamiento desde las ciencias sociales. Ed. del Autor.

Molas Font, M.a D. (ed.). 2007. Violencia deliberada. Las raíces de la violencia patriarcal. Barcelona: Icaria.

Molas Font, M.a D., Guerra, S., Huntingford, E. y Zaragoza, J. (eds.). 2006. La violencia de género en la Antigüedad. Madrid: Instituto de la Mujer.

Moreira, I. 2006. "Violence, Purification and Mercy in the Late Antiquity Afterlife», en H. A. Drake (ed.), Violence in Late Antiquity. Perceptions and Practices: 145-154. Santa Barbara: University of California, Ashgate Ed.

Núñez de Paz, M. a I. 2015. «Auctoritas y mujeres romanas. ¿Ejercicio o sumisión?». Arenal 22.2 (julio-diciembre): 347-387.

Oroz, J. y Marcos, A. (trad.). 1982. San Isidoro de Sevilla, Etimologías, vols. I y II. Madrid: BAC.

Osaba, E. 2011. "Las raíces de la violencia. Las fuentes del derecho visigodo», en M.a J. Fuente y R. Morán (eds.), Raíces profundas. La violencia contra las mujeres (Antigüedad y Edad Media): 125-148. Madrid: Ediciones Polifemo.
Osaba, E. 2013. "Las mujeres en la sociedad visigoda de los siglos VI-VII», en R. Rodríguez López y M. a J. Bravo Bosch (eds.), Mulier. Algunas Historias e Instituciones de Derecho Romano: 109-134. Madrid: Dykinson.

Palacios Royán, J. 1978. Leandro de Sevilla, «De institutione virginum» (texto latino y traducción). Perficit. Publicación mensual de Estudios Clásicos IX, (115-118): 93-132 (texto latino) y 133-164 (traducción).

Pavón, P. 2011. «El uxoricidio de Iulia Maiana, manu mariti interfecta (CIL XIII, 2182)». Habis 42: 253-262.

Pedregal, A. 2015. «Discurso trasgresor para cuerpos (auto) controlados. La dominación de las mujeres en la Iglesia antigua», en J. Fernández Ubiña, A. J. Quiroga y P. Ubric (coords.), La Iglesia como sistema de dominación en la Antigüedad Tardía: 255-273. Granada: Eug.

Pérez Cantó, P. (ed.). 2009. El origen histórico de la violencia contra las mujeres. Madrid: Dilema.

Rivas Rebaque, F. 2002. «Protagonismo y marginación de la mujer en el cristianismo primitivo: Asia Menor», en X. Quinzá Lleó y G. Urríbarri Bilbao, Responsabilidad y diálogo. Homenaje a Jose Joaquín Alemany Briz, S. J. (1937-2001): 385-414. Madrid: Universidad Pontificia de Comillas.

Sánchez Romero, M. 2007. "Mujeres y estrategias pacíficas de resolución de conflictos: el análisis de las sociedades prehistóricas», en M.a D. Molas Font (ed.), Violencia deliberada. Las raíces de la violencia patriarcal: 39-56. Barcelona: Icaria.

Sanz Serrano, R. 2000. "Las relaciones de dependencia como factor de cristianización en la Península Ibérica: grupos de edad y cristanización», en M.a del M. Myro, J. Miguel Casillas, J. Alvar y D. Plácido (eds.), Las edades de la dependencia durante la Antigüedad: 395424. Madrid: Ediciones Clásicas.

Schroeder, J. A. 2004. «John Chrysostom's Critique of Spousal Violence». Journal of Early Christian Studies 12.4 (winter): 413-432.

Segura Graíño, C. 2008. "La violencia sobre las mujeres en la Edad Media. Estado de la cuestión». Clio \& Crimen: La violencia de género en la Edad Media 5: 24-38.

Shaw, B. 1987. "The Family in Late Antiquity: The Experience of Augustine». Past and Present 115: 3-51.

Sotomayor, M. 2002. Discípulos de la Historia. Estudios sobre el cristianismo. Granada: Public. Universidad de Granada.

Sotomayor, M. y Fernández Ubiña, J. (coords.). 2005. El concilio de Elvira y su tiempo. Granada: Public. Universidad de Granada.

Teschendorff, C. 2005. «Mujer,familia y matrimonio en el Imperio Romano», en C. Alfaro y E. Tébar (eds.), Protai gynaikes: Mujeres próximas al poder en la Antigüedad (SEMA V-VI): 117-134. Valencia: Universidad de Valencia.

Treggiari, S. 1991. Roman marriage: iusti coniuges from the time of Cicero to the time of Ulpian. Oxford: Oxford U. P.

Urbanik, J. 2013. «Marriage and Divorce in the Late Antique. Legal Practice and Legislation», en E. Osaba (ed.), Derecho, Cultura y Sociedad en la Antigüedad Tardía: 259-274. Bilbao: Servicio Edición Universidad de País Vasco.

Urdeix, J. (dir.). 2011. San Isidoro de Sevilla, Los oficios eclesiásticos (según el texto editado por Jacques-Paul Migne: PL., vol. 84, col. 737-826 (Cuadernos Phase 200). Barcelona: Centre de Pastoral litúrgica.

Vives, J. 1963. Concilios visigóticos e hispanorromanos. BarcelonaMadrid: CSIC-Instituto Enrique Flórez.

Wemple, S. F. 1981. Women in Frankish-Society. Marriage and the Cloister, 500 to 900. Philadelphia: University of Pennsylvania Press. 